\title{
Knockdown of IncRNA AL928768.3 inhibits multiple myeloma cell proliferation by inducing cell cycle arrest in G0/G1 phase
}

\author{
Qian Shen $^{1 \#}$, Qi Jiang ${ }^{1 \#}$, Zhirong Cong ${ }^{1}$, Yin Zhou ${ }^{1}$, Xiaoxiao Huang ${ }^{2}$, Li Zhu ${ }^{1}$, Xiaohong Xu ${ }^{1}$, Juan Qian ${ }^{3}$ \\ ${ }^{1}$ Department of Hematology \& Lymphoma, Affiliated Tumor Hospital of Nantong University, Nantong, China; ${ }^{2}$ Department of Laboratory, \\ Affiliated Tumor Hospital of Nantong University, Nantong, China; ${ }^{3}$ Department of Hematology, Affiliated Hospital of Nantong University, \\ Nantong, China. \\ Contributions: (I) Conception and design: Q Shen, Q Jiang; (II) Administrative support: X Huang, Z Cong; (III) Provision of study materials or \\ patients: X Xu; (IV) Collection and assembly of data: Y Zhou, L Zhu; (V) Data analysis and interpretation: J Qian; (VI) Manuscript writing: All \\ authors; (VII) Final approval of manuscript: All authors. \\ \#These authors contributed equally to this work. \\ Correspondence to: Juan Qian. Department of Hematology, Affiliated Hospital of Nantong University, Nantong, China. Email: juanqian116@163.com; \\ Xiaohong Xu. Department of Hematology \& Lymphoma, Affiliated Tumor Hospital of Nantong University, Nantong, China. Email: xhx107@163.com.
}

Background: Multiple myeloma (MM) is a B-lymphocyte-derived malignancy. It ranks as the second most common hematological malignancy, with relatively high morbidity and mortality. However, the molecular mechanisms of MM occurrence and development remain elusive. This study found that long noncoding RNA AL928768.3 ( $\operatorname{lncRNA} A L$ ) was abnormally expressed in MM samples. However, the effect and molecular mechanism of $\operatorname{lncRNA} A L$ on the occurrence and development of MM remains unclear.

Methods: Bone marrow fluids of MM patients $(n=54)$ and volunteers $(n=13)$ were collected and CD138 cells were isolated. The expression level of $\operatorname{lnc} R N A A L$ in $M M$ cells was detected by quantitative real-time polymerase chain reaction (qRT-PCR), and the correlation between the expression level of $\operatorname{lncRNA} A L$ and the clinicopathological features of patients was analyzed. Lentiviral vectors targeting $\ln R N A A L$ knockdown were constructed and transfected into cells. After transfection, the effects of $\ln R N A A L$ knockdown on MM cell proliferation and the cell cycle were detected by the CCK-8 assay, clone formation assay, and flow cytometry. The effect of $\operatorname{lnc} R N A A L$ knockdown on MM cell cycle-related proteins was detected by Western blot. In addition, tumorigenicity experiments were performed in nude mice to detect the effect of $\operatorname{lnc} R N A A L$ knockdown on MM cell proliferation in vivo.

Results: $L n c R N A A L$ was highly expressed in MM patient samples and cell lines, and was significantly correlated with the disease stage of patients. Knockdown of $\operatorname{lncRNA} A L$ significantly inhibited the proliferation and colony formation of MM cells and induced cell cycle arrest in G0/G1 phase. Western blot analysis showed that knockdown of $\ln R N A A L$ significantly inhibited the expression of CDK2 and cyclin D1 and promoted the expression of cyclin suppressor p21. Knockdown of $\operatorname{lncRNA} A L$ significantly inhibited the proliferation of $M M$ cells in nude mice.

Conclusions: $\operatorname{LncRNA} A L$ was highly expressed in MM patients. Knockdown of this gene significantly inhibited the proliferative ability of MM cells and induced cell cycle arrest in G0/G1 phase. Therefore, $\operatorname{lncRNA} A L$ may be a novel biological target molecule for the early diagnosis, treatment, and prognostic evaluation of $M M$ patients.

Keywords: Multiple myeloma (MM); long non-coding RNAs (lncRNAs); G0/G1 phase

Submitted Nov 18, 2021. Accepted for publication Feb 11, 2022.

doi: 10.21037/atm-21-6710

View this article at: https://dx.doi.org/10.21037/atm-21-6710 


\section{Introduction}

Long non-coding RNAs (lncRNAs) are non-coding RNAs over $200 \mathrm{bp}$ in length which are located in the nucleus or cytoplasm $(1,2)$. With the development of sequencing technology, an increasing number of lncRNAs have been discovered and their biological functions have been partially clarified. A significant amount of research has proven that the abnormal expression of lncRNAs is closely related to the occurrence and development of a variety of diseases (cardiovascular, tumor, immune) (3-5). Existing studies indicate that although non-coding RNAs do not encode proteins, they are involved in various levels of important biological processes as regulatory molecules, including epigenetic regulation, transcriptional regulation, and post-transcriptional regulation $(6,7)$. At present, more than 200 lncRNAs have been identified to be related to the occurrence and development of a variety of tumors, and their abnormal expression is closely related to tumorigenesis, metastasis, and tumor stage (8). Therefore, lncRNAs have great potential in the treatment and diagnosis of cancer, and lncRNA-based diagnosis and targeted therapy strategies should be developed to bring about a new model for cancer research.

Multiple myeloma (MM) is a plasma cell malignant proliferative disease characterized by abnormal proliferation of bone marrow plasma cells accompanied by overproduction of monoclonal immunoglobulin or light chain (M protein) (9), which causes damage to relevant organs or tissues. As the second most common hematological malignancy, $M M$ has a global incidence of about 20,000-30,000 per 100,000 people (10), with relatively high morbidity and mortality rates. Monoclonal gammopathy of unknown significance (MGUS) and smoldering MM (SMM) are considered to be early stages in the progression of MM, with the annual incidence of progressing to symptomatic MM being $1 \%$ and $10 \%$, respectively. The mechanisms of MGUS malignant transformation and SMM progression are still unclear, but genetic abnormalities, including mutations of tumor suppressor genes or oncogenes, play an important role. Despite significant advances in conventional chemotherapy, targeted therapies, stem cell transplantation, and nanomedicine, MM remains incurable, with inevitable relapse and a poor 5-year survival rate (11). It is urgent to find new methods to improve the early diagnosis and clinical treatment of MM. Studies have suggested that lncRNA is closely related to MM in various stages of plasma cell carcinogenesis events, such as $\mathrm{IgH}$ translocation, hyperdiploid and $N R A S / B R A F$ gene activation (12). Different lncRNAs have different expressions, some are upregulated and some are down-regulated, and participate in the complex biological mechanism of gene change. When the cancerous plasma cells reached the final plasma cell leukemia, most of the key lncRNAs were changed. Therefore, the mechanism of lncRNA is closely related to the malignancy of MM (13). A large amount of research has shown that lncRNAs play an important role in the transcription pattern and functioning of MM. For example, knockdown of lncRNA SNHG16 significantly inhibits the proliferation of MM cells, suggesting that SNHG16 is a new therapeutic target for MM (14). In addition, lncRNA NEAT1 is highly expressed in MM samples, and silencing this gene can enhance the effect of traditional chemotherapy (15). The AL928768.3 gene is located on human chromosome 14 . It is a 359 -bp-long lncRNA that does not encode proteins. It is up-regulated in patients with rheumatoid arthritis, thereby serving as a new biomarker of rheumatoid arthritis (16). Our previous study has analyzed lncRNA expression profiles in 5 MM samples and 5 control samples by RNA sequencing (data not published) and found that $\operatorname{lncRNA} A L 928768.3(\operatorname{lnc} R N A A L)$ was upregulated in $M M$ tissues. However, the function of $\operatorname{lnc} R N A A L$ in tumor tissues, especially in $M M$, remains unclear. Therefore, this study aims to investigate the expression and biological function of $\operatorname{lnc} R N A A L$ in $M M$ and explore the preliminary molecular mechanisms, so as to provide molecular targets for the early diagnosis and targeted therapy of MM.

We present the following article in accordance with the ARRIVE reporting checklist (available at https://atm. amegroups.com/article/view/10.21037/atm-21-6710/rc).

\section{Methods}

\section{Collection of clinical samples}

Bone marrow fluid from 54 MM patients and 13 volunteers (control) and relevant clinical data were collected from January 2019 to early March 2021. There were 31 male patients and 23 female patients, aged from 45 to 80 years, including 35 immunoglobulin $\mathrm{G}$ type patients, 12 immunoglobulin A type patients, 7 light chain type patients, 10 International Staging System (ISS) stage I patients, 18 ISS stage II patients, and 26 ISS stage III patients. Within 30 min after sample collection, CD $138^{+}$ cells in the bone marrow fluid were separated and collected 
in a biosafety cabinet. The mRNA was extracted from tissues and reverse transcribed into cDNA for preservation.

All procedures performed in this study involving human participants were in accordance with the Declaration of Helsinki (as revised in 2013). The study was approved by the Ethics Committee of the Affiliated Tumor Hospital of Nantong University (No. 20184294) and informed consent was taken from all the participants.

\section{Cell culture}

Human MM cell lines MN.1S, NCI-H929, RIMP 8226, and U266 were all purchased from Cell Center of the Chinese Academy of Medical Sciences, and normal plasma cells (nPCs) from healthy participants were isolated and cultured. The cells were cultured in RPMI-1640 medium (10\% fetal bovine serum) containing $100 \mathrm{U} / \mathrm{mL}$ penicillin and $100 \mathrm{mg} / \mathrm{mL}$ streptomycin and maintained in a $37^{\circ} \mathrm{C}$ incubator with $5 \% \mathrm{CO}_{2}$ and saturated humidity.

\section{Real-time polymerase chain reaction (RT-PCR)}

Total RNA was extracted by the Trizol method from bone marrow fluid and corresponding cell lines from MM patients and controls. The concentration was determined by Nanodrop 2000. RNA was stored at $-80{ }^{\circ} \mathrm{C}$ for future use. Specific primers for related genes were designed based on the nucleotide sequences published by GenBank. The reaction was performed by fluorescence quantitative PCR, and GADPH was used as the reference gene. The relative quantitative determination of each gene was carried out by the double standard curve method. The relative expression of each gene was calculated by the $2^{-\Delta \Delta \mathrm{Ct}}$ method, where $\Delta \mathrm{Ct}$ = target gene Ct value - internal reference gene Ct value, and $\Delta \Delta \mathrm{Ct}=$ transfection group $\Delta \mathrm{Ct}-$ control group $\Delta \mathrm{Ct}$. The correlation of the expression level of $\operatorname{lnc} R N A A L$ with the clinical stage and prognosis of patients was determined by combined analysis of the expression level, the patient's stage, and clinical data. Primer sequences of $\operatorname{lnc} R N A A L$ and glyceraldehyde phosphate dehydrogenase gene (GAPDH) were designed according to a previous study (16).

Primer sequences of $\operatorname{lnc} R N A A L$ :

Forward: 5'-CGTGACCTCTGTGGCTGCTA-3', Reverse: 5'-TTGTGATGTTGGCGGTTAGTGG-3'; GAPDH:

Forward: 5'-GAGTCCACTGGCGTCTTCAC-3', Reverse: 5'-ATCTTGAGGCTGTTGTCATACTT CT-3'.

\section{Transfection experiment}

ShRNA was designed and synthesized by Shanghai Sangon Biotechnology Co., Ltd. according to the lncRNA AL gene sequence (shRNA: 5'-AGGATCCAAGCTTGGATAGTATT-3'). Lentiviral vectors were also constructed. MM cells in the exponential growth phase were collected, counted, and inoculated in 6-well plates. Then, they were cultured in a $37^{\circ} \mathrm{C}$ incubator with $5 \% \mathrm{CO}_{2}$. Before transfection, the cells were cultured with serum-free medium and washed twice. Ten MOI viruses were added to transfect the cells, which were then incubated for $2 \mathrm{~h}$ in a $37^{\circ} \mathrm{C}$ incubator. The incubator was gently shaken every $15 \mathrm{~min}$. Then, $2 \mathrm{~mL}$ medium was added, and the culture plates were placed in an incubator for $48 \mathrm{~h}$.

\section{CCK-8 assay}

Cells in good condition were washed twice with precooled PBS buffer, digested, and inoculated into a 96-well plate. Then, the plate was placed in a $37{ }^{\circ} \mathrm{C}$ incubator with $5 \%$ $\mathrm{CO}_{2}$ for cultivating 48,72 , and $96 \mathrm{~h}$. Next, $10 \mu \mathrm{L}$ of CCK8 solution was added to each well, and the plate was placed in the incubator for $4 \mathrm{~h}$. The absorbance at $450 \mathrm{~nm}$ was measured with a microplate reader.

\section{Colony formation assay}

Cells at the logarithmic growth phase in each group were collected, digested with $0.25 \%$ trypsin, and blown into single cells. The cells were suspended in RPMI-1640 medium with $10 \%$ fetal bovine serum for reserve. After diluting the cell suspension, cells were inoculated into a 6-well plate at a density of 500 cells per well and gently rotated for even dispersion. The cells were cultured in a $37{ }^{\circ} \mathrm{C}$ cell incubator with $5 \% \mathrm{CO}_{2}$, and the medium was replaced every 3 days. The culture was terminated when visible colonies appeared 14 days later. The supernatant was discarded, then cells were carefully washed twice with PBS and fixed with 4\% paraformaldehyde for $15 \mathrm{~min}$. The fixative solution was removed, and $2 \mathrm{~mL}$ of $1 \%$ crystal violet staining solution was added to stain the cells for $10 \mathrm{~min}$. The staining solution was slowly washed with running water. The cells were dried in air. Photos were taken, and the number of cells was counted.

\section{Cell cycle assay}

Transfected cells were collected, washed with $3 \mathrm{~mL}$ PBS, and 
fixed with $75 \%$ precooled ethanol at $4{ }^{\circ} \mathrm{C}$ for $24 \mathrm{~h}$. Then, the cells were suspended in $0.5 \mathrm{~mL} \mathrm{PI/RNase}$ for staining. The cells were incubated at room temperature in the dark for $30 \mathrm{~min}$ and detected by flow cytometry within $1 \mathrm{~h}$.

\section{Western blot}

The transfected cells were collected and washed with PBS. Then, $100 \mu \mathrm{L}$ precooled RIPA lysis buffer (containing $1 \mu \mathrm{L}$ PMSF) was added to lyse the cells, and the mixture was evenly distributed by gently shaking. The cells were lysed for $30 \mathrm{~min}$ on ice. Then, the lysate was centrifuged and the supernatant was collected. The proteins were quantified by the BCA protein quantification kit. Separation and concentration gels were prepared by conventional methods. The protein sample was added to the gel pores (70 $\mu \mathrm{g}$ per lane) for electrophoresis at a constant voltage of $40 \mathrm{~V}$ (concentration gel)/100 V (separation gel) until bromophenol blue reached the edge of the gel. After the gel was transferred to the membrane, the membrane was blocked for $2 \mathrm{~h}$ with $8 \%$ skim milk powder at room temperature. Primary antibodies CDK2 (1:800), cyclin D1 $(1: 1,000)$, p21 (1:1,000), cyclin E $(1: 1,000)$, CDK4 (1:800), CDK6 (1:800), and GAPDH $(1: 1,000$; as the internal reference) diluted with $5 \%$ BSA were added for incubation overnight at $4{ }^{\circ} \mathrm{C}$. The membrane was washed 3 times with TBST buffer solution. Next, the secondary antibody diluted with $5 \%$ BSA $(1: 2,000)$ was added and incubated at room temperature for $1.5 \mathrm{~h}$. Lastly, solution A and solution B of the ECL developer were mixed in equal volume and then added to the membrane for development. Tanon 5200 was used to capture images.

\section{Tumorigenicity experiment in nude mice}

Ten male nude mice aged 6-8 weeks were purchased from Shanghai Laboratory Animal Research Center. The mice were divided into two groups: shNC group $(\mathrm{n}=5)$ and shAL1 group $(n=5)$. Transfected cells were collected and the cell density was adjusted to $1 \times 10^{7} / \mathrm{mL}$. Then, $100 \mu \mathrm{L}$ of cell suspension was mixed with $100 \mu \mathrm{L}$ Matrigel, and the mixture was subcutaneously transplanted into the right side of the nude mice. The tumor size was measured from the 10 th day, and the measurement was taken every 5 days. The tumor volume was calculated by the formula $\mathrm{V}$ (volume) $=\left(\mathrm{L} \times \mathrm{W}^{2}\right) / 2$, where $\mathrm{L}$ was the tumor length and $\mathrm{W}$ was the tumor width. The nude mice were sacrificed 30 days later, and the tumors were stripped and weighed. Then, the tumors were stored at $-80{ }^{\circ} \mathrm{C}$ for total RNA and protein extraction in subsequent analysis.

Animals experiments were performed under a project license (No. 20183518-051) granted by the Ethics Committee of the Affiliated Tumor Hospital of Nantong University, in compliance with Shanghai Laboratory Animal Research Center's guidelines for the care and use of animals.

\section{Statistical analysis}

SPSS 19.0 was used for data analysis. Measurement data were expressed as mean \pm standard deviation. Measurement data that conformed to the normal distribution were compared by the $t$-test or analysis of variance (ANOVA), and data that did not conform to the normal distribution were compared by the non-parametric rank sum test. The Chi-square test was used for count data. $\mathrm{P}<0.05$ was considered statistically significant.

\section{Results}

\section{LncRNA AL is bighly expressed in MM bone marrow fluid and cell lines}

To explore the expression of $\operatorname{lnc} R N A A L$ in MM bone marrow fluid, fluorescence quantitative PCR was used to detect the expression of $\operatorname{lnc} R N A A L$ in 54 MM samples and 13 control samples. The results demonstrated that the expression of $\operatorname{lnc} R N A A L$ was much higher in MM samples than that in normal samples (Figure 1A). Further analysis showed that $\operatorname{lnc} R N A A L$ expression increased gradually with the advancement of MM ISS stage (Figure $1 B$ ). In MM cell lines (MN.1S, NCI-H929, RIMP 8226, and U266 cells) and nPCs, it was found that compared with nPCs, the expression of $\ln R N A A L$ in MM cells was significantly increased, with the highest expression levels in RIMP 8226 and U266 cells (Figure 1C). Therefore, MM cell lines RIMP 8226 and U266 were selected for subsequent functional experiments and molecular mechanism studies.

\section{Knockdown of lncRNA AL inbibits MM cell proliferation and induces cell cycle arrest in G0/G1 phase}

To further study the effect of $\operatorname{lncRNA} A L$ on MM cell proliferation, lentiviral vectors targeting the $\ln c R N A A L$ sequence (shAL-1) and blank control vectors (shNC) were first constructed. Then, RIMP 8226 and U266 cells 
A

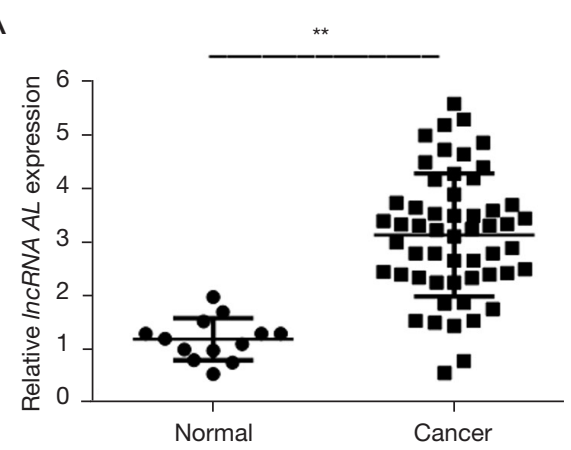

C

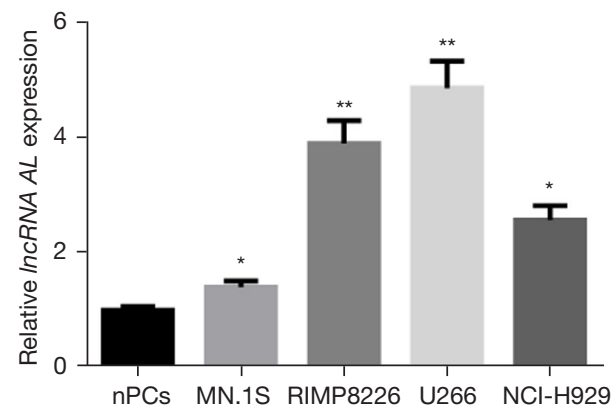

B

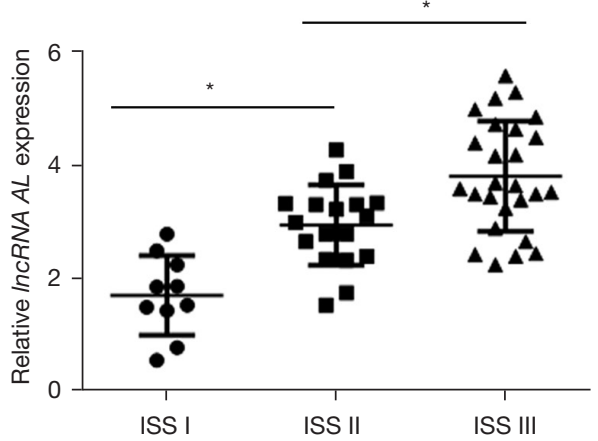

Figure 1 LncRNA $A L$ is highly expressed in MM samples and cell lines. (A) Fluorescence quantitative PCR detected the expression of lncRNA AL in $54 \mathrm{MM}$ samples and 13 normal samples; (B) fluorescence quantitative PCR detected the expression of $\operatorname{lncRNA} A L$ in different ISS stages of MM; (C) fluorescent quantitative PCR detected the expression of $n c R N A A L$ in $M M$ cell lines and ${ }_{n} P C s .{ }^{*} \mathrm{P}<0.05 ;{ }^{* *} \mathrm{P}<0.01$. LncRNA, long non-coding RNA; $\operatorname{lncRNA} A L$, $\operatorname{lnc} R N A$ AL928768.3; MM, multiple myeloma; PCR, polymerase chain reaction; ISS, International Staging System; nPCs, normal plasma cells.

were transfected with these constructed vectors. The expression efficiency of $\operatorname{lnc} R N A A L$ in cells was detected by fluorescence quantitative PCR. The results showed that compared with shNC, shAL-1 could significantly reduce the expression level of $\operatorname{lnc} R N A$ AL in MM cells (Figure $2 A$ ). The effect of $\operatorname{lncRNA} A L$ knockdown on MM cell proliferation was further detected by the CCK- 8 assay. The results showed that compared with shNC, shAL-1 could significantly inhibit MM cell proliferation (Figure $2 B$ ). The colony formation assay demonstrated that compared with shNC, shAL-1 could significantly suppress the colony formation of MM cells (Figure 2C).

In addition, flow cytometry was also performed to detect the effect of $\operatorname{lnc} R N A A L$ knockdown on MM cells. The results showed that compared with shNC, shAL-1 could significantly increase cells in G0/G1 phase and decrease cells in S and G2/M phase (Figure 2D). The above results indicated that knockdown of $\operatorname{lnc} R N A A L$ could significantly inhibit the proliferation of $M M$ cells, resulting in cell cycle arrest in G0/G1 phase.

\section{Knockdown of IncRNA AL significantly affects the expression of MM cell cycle-related proteins}

The above experimental results showed that $\operatorname{lnc} R N A A L$ knockdown could inhibit MM cell proliferation and induce cell cycle arrest in G0/G1 phase. To further study the effect of $\operatorname{lncRNA} A L$ knockdown on MM cell cycle regulatory proteins, we conducted Western blot analysis. Western blot results showed that in U266 cells, compared with shNC, shAL-1 could significantly inhibit the expression of CDK2 and cyclin D1 and significantly promote the expression of p21, while the expression levels of cyclin E, CDK4, and CDK6 were not significantly affected (Figure 3). In RIMP 8226 cells, compared to shNC, shAL-1 significantly inhibited the expression of CDK2, cyclin D1, and cyclin $\mathrm{E}$ and significantly promoted the expression of $\mathrm{p} 21$, but had no significant effect on the expression of CDK4 and CDK6 (Figure 3). These results indicated that knockdown of $\operatorname{lnc} R N A A L$ in MM cells could directly and significantly inhibit the expression of CDK2 and cyclin D1 and promote 


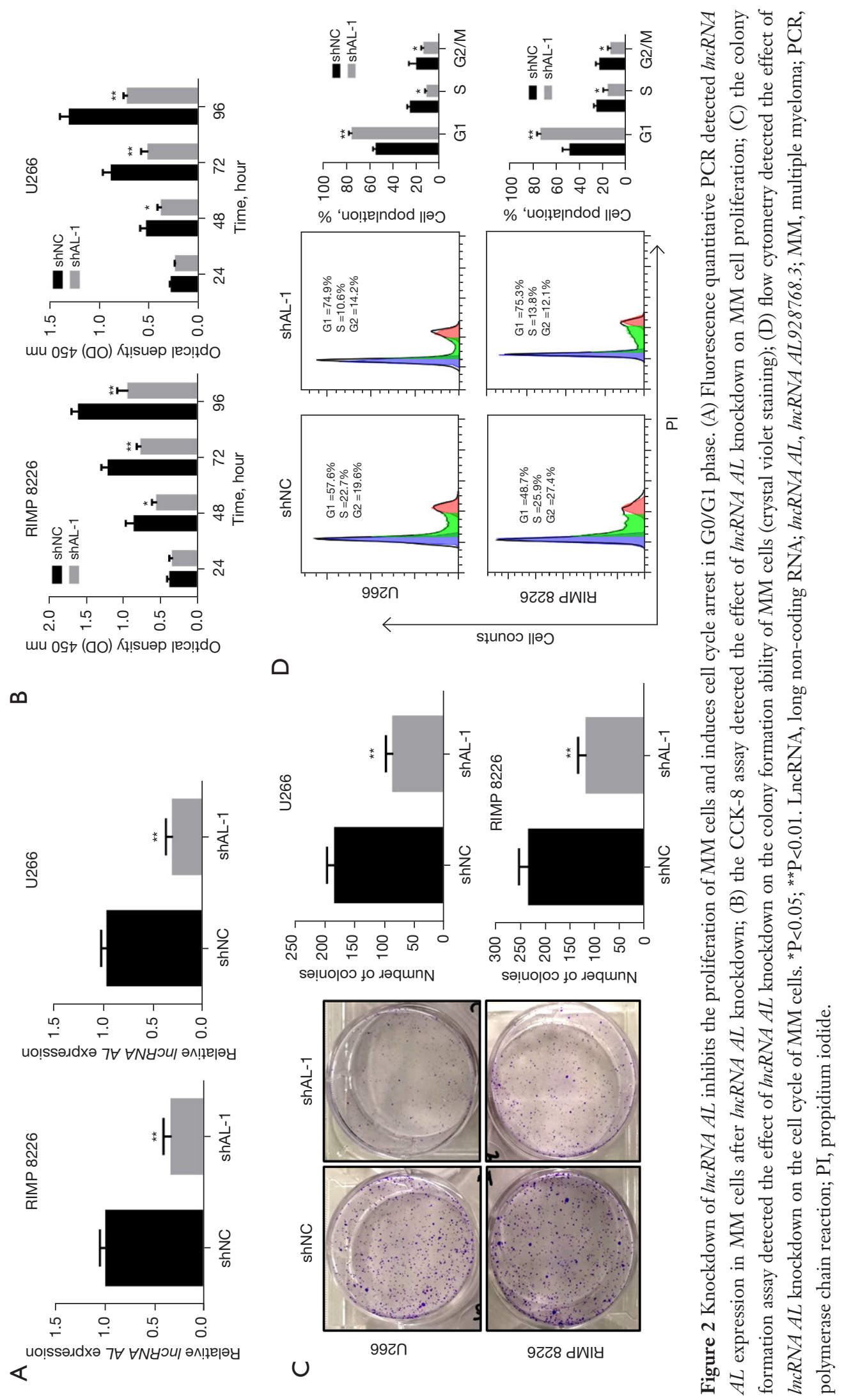



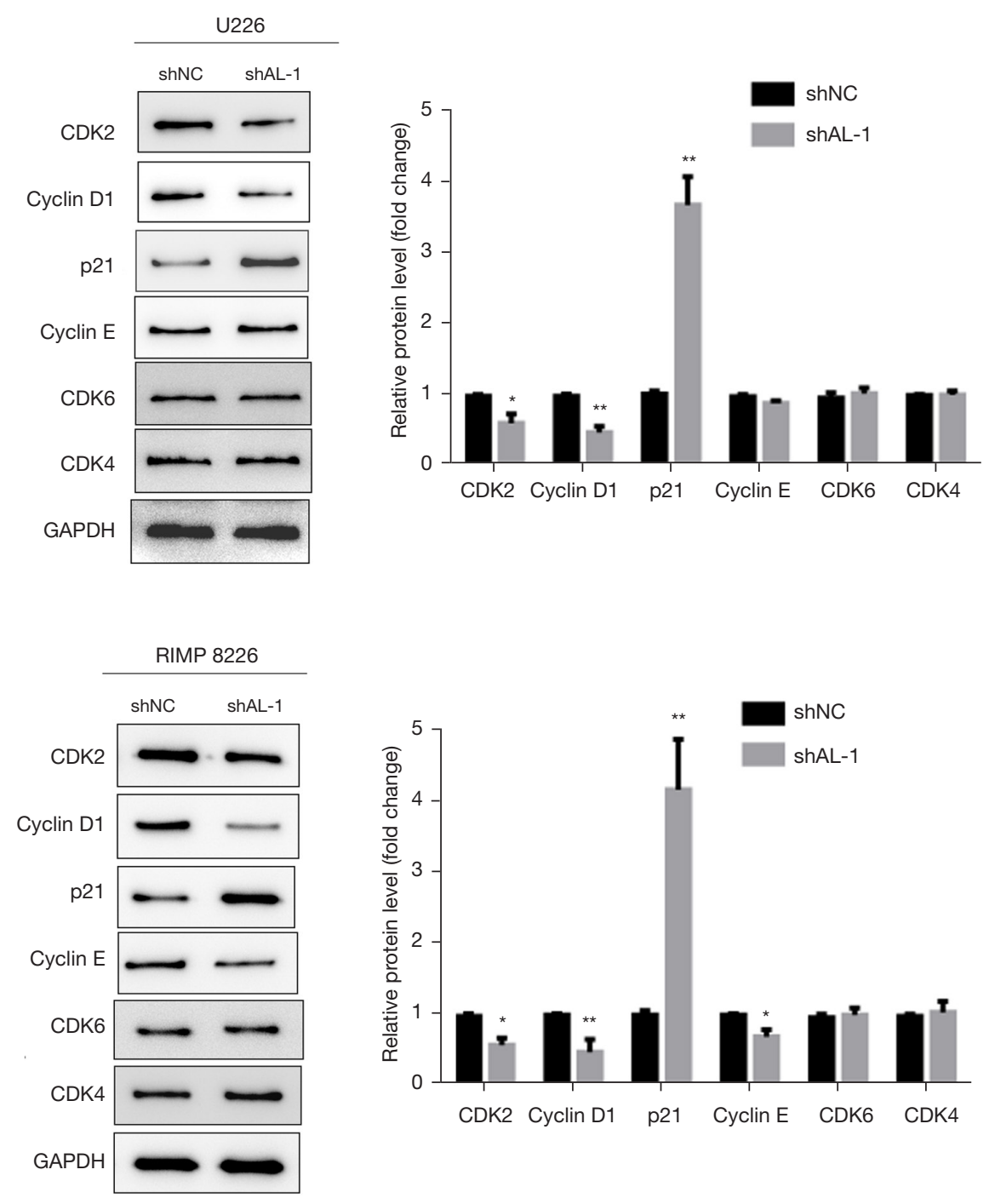

Figure 3 Western blot detected the effect of $\operatorname{lnc} R N A A L$ knockdown on MM cell cycle-related proteins. ${ }^{*} \mathrm{P}<0.05$; ${ }^{* *} \mathrm{P}<0.01$. LncRNA, long non-coding RNA; $\operatorname{lncRNA} A L$, $\operatorname{lncRNA} A$ L928768.3; MM, multiple myeloma.

the expression of p21, inducing cell cycle arrest in G0/G1 phase.

\section{Knockdown of lncRNA AL significantly inbibits MM proliferation in nude mice}

To further verify the effect of $\operatorname{lnc} R N A A L$ knockdown on MM cell proliferation in vivo, a tumorigenicity experiment was performed in nude mice. The results of the tumorigenicity experiments in nude mice showed that compared with the shNC group, the volumes (Figure 4A) and weights (Figure $4 B$ ) of the transplanted tumors in the
shAL-1 group were significantly reduced. Fluorescence quantitative PCR results showed that compared with the shNC group, the shAL-1 group had a significantly reduced expression level of $\operatorname{lnc} R N A A L$ in transplanted tumor tissues (Figure 4C). Western blot further detected the expression levels of CDK2, cyclin D1, and p21 in the transplanted tumor tissues. The results showed that compared to the shNC group, the shAL-1 group had lower expression levels of CDK2 and cyclin D1 and a higher expression level of p21 in the transplanted tumor tissues (Figure 4D). These results indicated that knockdown of $\ln R N A A L$ could significantly inhibit the proliferative ability of $M M$ cells in nude mice. 
A

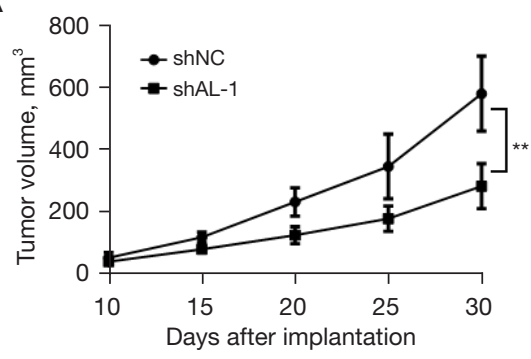

B

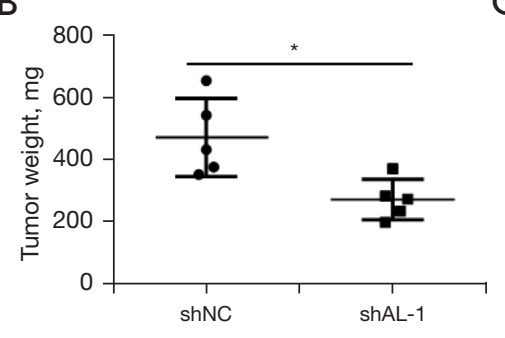

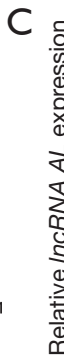



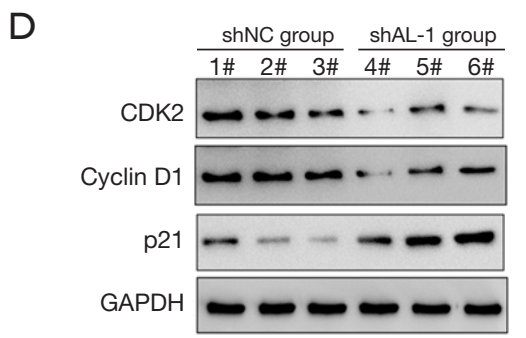

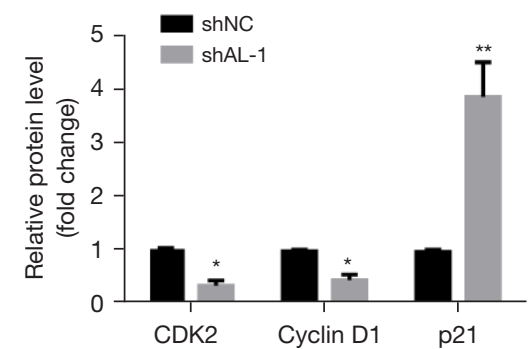

Figure 4 Knockdown of $l n c R N A A L$ significantly inhibits MM cell proliferation in nude mice. (A) Effect of $l n c R N A A L$ knockdown on MM cell growth in nude mice; (B) weights of transplanted tumors in the shNC group and shAL-1 group 30 days after tumor transplantation; (C) fluorescence quantitative PCR detected the expression of $\operatorname{lncRNA} A L$ in the transplanted tumor tissues; (D) Western blot detected the expression of CDK2, cyclin D1, and $\mathrm{p} 21$ in transplanted tumor tissues. ${ }^{*} \mathrm{P}<0.05$; ${ }^{*} \mathrm{P}<0.01$. LncRNA, long non-coding RNA; lncRNA $A L$, lncRNA AL928768.3; MM, multiple myeloma; PCR, polymerase chain reaction; GAPDH, glyceraldehyde phosphate dehydrogenase gene.

\section{Discussion}

MM is a hematological malignancy characterized by clonal proliferation of bone marrow plasma cells. Abnormal secretion of monoclonal immunoglobulin can be detected in the serum of the absolute majority of patients, and multiple organ and multiple system injuries may occur clinically (17). With the continuous progress of diagnosis and treatment technologies, the overall survival and quality of life of MM patients have been greatly improved, but it remains an incurable malignant tumor (18). In recent years, lncRNAs have been found to play extremely important roles in the course of various neoplastic diseases, including MM $(19,20)$. This study first found that $\operatorname{lnc} R N A A L$ was highly expressed in $M M$ samples and cell lines and was significantly correlated with the ISS stage of patients. In addition, both in vivo and in vitro experiments confirmed that knockdown of $\operatorname{lnc} R N A A L$ significantly inhibited the proliferative ability of MM cells.

A significant amount of research has shown that lncRNAs play an important role in the occurrence and development of a variety of tumors and can be used as potential biomarkers for the early diagnosis or targeted therapy of tumors $(21,22)$. For example, the increased content of lncRNA TUG1 in the peripheral blood of $M M$ patients makes it a potential diagnostic marker for MM (23). LncRNA NR_046683 can be used as a potential drug target and novel biomarker to predict the prognosis of MM patients (24). Therefore, identification of new lncRNAs that play important roles in the occurrence and development of MM is of great significance for the early diagnosis and targeted therapy of MM. LncRNA AL is a newly discovered lncRNA and is a novel biomarker of rheumatoid arthritis (16). The present study first found that $\operatorname{lnc} R N A A L$ was highly expressed in MM samples and was associated with the ISS stage of patients. Cell function experiments showed that knockdown of $\operatorname{lncRNA} A L$ significantly inhibited the proliferation and colony formation of MM cells. MM is a malignant disease with abnormal proliferation of clonal plasma cells, so inhibition of cell proliferation is one of the main strategies for the treatment of MM (25). Further experiments in this study showed that $\ln R N A A L$ could induce cycle arrest in MM cells, which led to an increase of cells in G0/G1 phase (period when cells stop dividing) and a corresponding decrease of cells in S and G2/M phase, thus inhibiting the proliferative ability of MM cells. Therefore, $\ln R N A A L$ can be used as a potential molecular target to inhibit MM proliferation. We further explore the effect of knockdown of $\ln R N A A L$ on the expression of cycle-related proteins.

The cell cycle is a process highly dependent on 
regulation by cyclin-suppressor proteins (p21, p15, and p17, etc.) and cyclin-dependent kinases (CDKs) (26). For example, cyclin D1 and cyclin E are important regulatory factors in the transition process from G0/G1 to $S$ phase. Cyclin D1 binds and activates its catalytic partners CDK4 or CDK6 to promote cell proliferation. CDK2 promotes cell transition from $S$ phase to $G 2 / M$ phase $(27,28)$. The results of the present study showed that knockdown of $\operatorname{lnc} R N A A L$ significantly inhibited the expression of CDK2 and cyclin D1 and promoted the expression of p2 1 in U266 cells. It also significantly inhibited the expression of CDK2, cyclin D1, and cyclin E in RIMP 8226 cells and promoted the expression of p21. Cyclin E can further phosphorylate $\mathrm{Rb}$ to promote cell division, and can phosphorylate and activate several proteins involved in DNA synthesis $(29,30)$. Therefore, we concluded that MM cell lines U266 and PIMP 8226 have different genetic backgrounds. Differences in the molecular regulation mechanisms and biological characteristics between the 2 cell lines resulted in certain differences in the impact of lncRNA AL knockdown on downstream target molecules, which further illustrates the heterogeneity and specificity of tumors and cell lines. Finally, tumorigenicity experiments in nude mice demonstrated that knockdown of $\operatorname{lnc} R N A A L$ significantly inhibited the proliferation of MM cells in vivo. The molecular mechanism by which $\operatorname{lnc} R N A$ AL regulates downstream gene expression remains to be further studied.

In conclusion, this study firstly demonstrated that $\operatorname{lnc} R N A A L$ was highly expressed in MM samples and cell lines and was associated with patient survival and ISS stage. In vivo and in vitro experiments confirmed that knockdown of $\operatorname{lncRNA} A L$ inhibited the proliferation of MM cells by inducing cell cycle arrest in G0/G1 phase and by inhibiting the expression of CDK2 and cyclin D1 and promoting the expression of $\mathrm{p} 21$. Therefore, $\operatorname{lncRNA} A L$ may be a new marker for the early diagnosis and prognostic evaluation of MM and may also be a therapeutic target for MM.

\section{Acknowledgments}

Funding: This work was supported by funding for the Health Commission of Nantong City (No. MA2020012) and the Nantong Science and Technology Project (No. HS2019003).

\section{Footnote}

Reporting Checklist: The authors have completed the
ARRIVE reporting checklist. Available at https://atm. amegroups.com/article/view/10.21037/atm-21-6710/rc

Data Sharing Statement: Available at https://atm.amegroups. com/article/view/10.21037/atm-21-6710/dss

Conflicts of Interest: All authors have completed the ICMJE uniform disclosure form (available at https://atm. amegroups.com/article/view/10.21037/atm-21-6710/coif). The authors have no conflicts of interest to declare.

Etbical Statement: The authors are accountable for all aspects of the work in ensuring that questions related to the accuracy or integrity of any part of the work are appropriately investigated and resolved. All procedures performed in this study involving human participants were in accordance with the Declaration of Helsinki (as revised in 2013). The study was approved by the Ethics Committee of the Affiliated Tumor Hospital of Nantong University (No. 20184294) and informed consent was taken from all the participants. Animals experiments were performed under a project license (No. 20183518-051) granted by the Ethics Committee of the Affiliated Tumor Hospital of Nantong University, in compliance with Shanghai Laboratory Animal Research Center's guidelines for the care and use of animals.

Open Access Statement: This is an Open Access article distributed in accordance with the Creative Commons Attribution-NonCommercial-NoDerivs 4.0 International License (CC BY-NC-ND 4.0), which permits the noncommercial replication and distribution of the article with the strict proviso that no changes or edits are made and the original work is properly cited (including links to both the formal publication through the relevant DOI and the license). See: https://creativecommons.org/licenses/by-nc-nd/4.0/.

\section{References}

1. Jathar S, Kumar V, Srivastava J, et al. Technological Developments in lncRNA Biology. Adv Exp Med Biol 2017;1008:283-323.

2. Ali T, Grote P. Beyond the RNA-dependent function of LncRNA genes. Elife 2020;9:60583.

3. Huang Y. The novel regulatory role of lncRNA-miRNAmRNA axis in cardiovascular diseases. J Cell Mol Med 2018;22:5768-75.

4. Robinson EK, Covarrubias S, Carpenter S. The how and why of lncRNA function: An innate immune 
perspective. Biochim Biophys Acta Gene Regul Mech 2020;1863:194419.

5. Ma Y, Zhang J, Wen L, et al. Membrane-lipid associated lncRNA: A new regulator in cancer signaling. Cancer Lett 2018;419:27-9.

6. Li J, Meng H, Bai Y, et al. Regulation of lncRNA and Its Role in Cancer Metastasis. Oncol Res 2016;23:205-17.

7. Peng WX, Koirala P, Mo YY. LncRNA-mediated regulation of cell signaling in cancer. Oncogene 2017;36:5661-7.

8. Bhan A, Soleimani M, Mandal SS. Long Noncoding RNA and Cancer: A New Paradigm. Cancer Res 2017;77:3965-81.

9. Kazandjian D. Multiple myeloma epidemiology and survival: A unique malignancy. Semin Oncol 2016;43:676-81.

10. Pawlyn C, Davies FE. Toward personalized treatment in multiple myeloma based on molecular characteristics. Blood 2019;133:660-75.

11. Rajkumar SV. Multiple myeloma: Every year a new standard? Hematol Oncol 2019;37 Suppl 1:62-5.

12. Butova R, Vychytilova-Faltejskova P, Souckova A, et al. Long Non-Coding RNAs in Multiple Myeloma. Noncoding RNA 2019;5:13.

13. Cui YS, Song YP, Fang BJ. The role of long non-coding RNAs in multiple myeloma. Eur J Haematol 2019;103:3-9.

14. Yang X, Huang H, Wang X, et al. Knockdown of lncRNA SNHG16 suppresses multiple myeloma cell proliferation by sponging miR-342-3p. Cancer Cell Int 2020;20:38.

15. Taiana E, Favasuli V, Ronchetti D, et al. Long noncoding RNA NEAT1 targeting impairs the DNA repair machinery and triggers anti-tumor activity in multiple myeloma. Leukemia 2020;34:234-44.

16. Sun L, Tu J, Liu C, et al. Analysis of lncRNA expression profiles by sequencing reveals that lnc-AL928768.3 and lnc-AC091493.1 are novel biomarkers for disease risk and activity of rheumatoid arthritis. Inflammopharmacology 2020;28:437-50.

17. Zanwar S, Nandakumar B, Kumar S. Immune-based therapies in the management of multiple myeloma. Blood Cancer J 2020;10:84.

Cite this article as: Shen Q, Jiang Q, Cong Z, Zhou Y, Huang X, Zhu L, Xu X, Qian J. Knockdown of $\operatorname{lncRNA}$ AL928768.3 inhibits multiple myeloma cell proliferation by inducing cell cycle arrest in G0/G1 phase. Ann Transl Med 2022;10(4):172. doi: 10.21037/atm-21-6710
18. Richardson PG, Beksaç M, Špička I, et al. Isatuximab for the treatment of relapsed/refractory multiple myeloma. Expert Opin Biol Ther 2020;20:1395-404.

19. Raimondi L, De Luca A, Giavaresi G, et al. NonCoding RNAs in Multiple Myeloma Bone Disease Pathophysiology. Noncoding RNA 2020;6:37.

20. Li J, Zou J, Wan X, et al. Roles of noncoding RNAs in drug resistance in multiple myeloma. J Cell Physiol 2020;235:7681-95.

21. Xu H, Yin Q, Shen X, et al. Long non-coding RNA CCAT2 as a potential serum biomarker for diagnosis and prognosis of multiple myeloma. Ann Hematol 2020;99:2159-71.

22. Feng $Y, W u M, H u S$, et al. LncRNA DDX11-AS1: a novel oncogene in human cancer. Hum Cell 2020;33:946-53.

23. Yin Q, Shen X, Cui X, et al. Elevated serum lncRNA TUG1 levels are a potential diagnostic biomarker of multiple myeloma. Exp Hematol 2019;79:47-55.e2.

24. Dong H, Jiang S, Fu Y, et al. Upregulation of lncRNA NR_046683 Serves as a Prognostic Biomarker and Potential Drug Target for Multiple Myeloma. Front Pharmacol 2019;10:45.

25. Rajkumar SV, Kumar S. Multiple myeloma current treatment algorithms. Blood Cancer J 2020;10:94.

26. Martínez-Alonso D, Malumbres M. Mammalian cell cycle cyclins. Semin Cell Dev Biol 2020;107:28-35.

27. Hume S, Dianov GL, Ramadan K. A unified model for the G1/S cell cycle transition. Nucleic Acids Res 2020;48:12483-501.

28. Tabassum N, Constantin TA, Cereser B, et al. A cell-cycle signature classifier for pan-cancer analysis. Oncogene 2020;39:6041-2.

29. Pang W, Li Y, Guo W, et al. Cyclin E: a potential treatment target to reverse cancer chemoresistance by regulating the cell cycle. Am J Transl Res 2020;12:5170-87.

30. Li J, Stanger BZ. Cell Cycle Regulation Meets Tumor Immunosuppression. Trends Immunol 2020;41:859-63.

(English Language Editor: C. Betlazar-Maseh) 